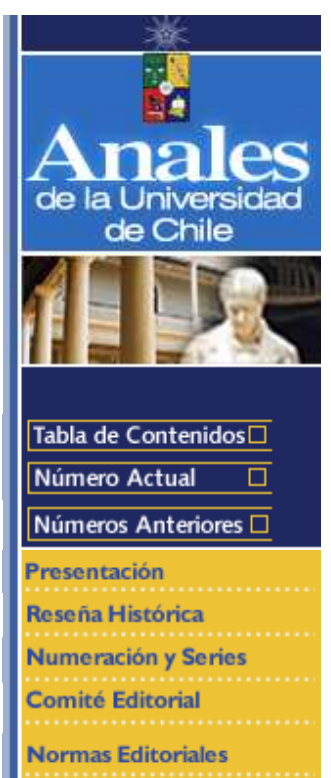

Anales de la Universidad de Chile Sexta Serie, Nº13, agosto de 2001 


\title{
Estudios
}

\section{[Naturaleza y artificio: paisaje fúnebre en la provincia de el Loa ]}

\author{
Benavente Aninat, María Antonia, Dra. \\ Departamento de Antropología Facultad de Ciencias \\ Sociales. Universidad de Chile
}

\section{Q RESUMEN}

"Advierte Louis Hartecoeur ${ }^{[1]}$ que una de las características del período prerromántico es el triunfo del jardín de tipo inglés (le jardín pittoresque), de planteamiento irregular y con un importante espacio para elementos fingidos, como las ruinas (1946:tu:40). En este ambiente se plantea a los cementerios y estructuras funerarias de nuestra área de estudio. Obviamente aquí la denominación de jardín, no es la propiamente europea, repleta de vegetación con matices otorgados por los diversos verdes, con sus arboledas propias. Sin embargo, podemos señalar que la vegetación fundamentalmente arbolada está dada para la región por lo inmensos chañares, pimientos, algarrobos y uno que otro arbusto, achaparrado de color marrón - otorgado por el polvo que acarrean los vientos de la zona. En este ámbito, las tumbas y diminutas esculturas, aparecen, como símbolos que manifiestan los individuos ante la muerte. Podriamos señalar que son invenciones artísticas, pensadas reflexivamente ya que concretizan ideas, pensamientos que poseen los individuos referente a dos aspectos: la vida por un lado y los bienes materiales por el otro. Son éstos a los que la persona se aferra. De ellos elige el signo fúnebre que lo va a representar en el momento de su muerte y por siempre. Esto nos permite reflexionar que a pesar de lo simple que pueda ser el lugar del sepulcro, existen un conjunto de códigos conceptuales tan significativos como persistentes en la mente de los individuos y sus comunidades.referente teórico del cual obtienen los patrones mortuorios traspasándolos a la iconografía fúnebre que le exige el ámbito cultural en el que se ven insertos. Iconografía que es universal, no surge de la nada, sino que es consensuada, la que si se traslada de una manera sincrética, es decir es un "melange" entre lo que esta aceptado para esos efectos pero adecuado al contexto del individuo. Porque sí son sepulturas que pertenecen a una persona real, antítesis de los antiguos enterramientos intramuros, que se localizaban al interior de las iglesias rurales de Chiu - Chiu, Lasana, Conchi y San Pedro de Atacama.

\section{Notas} (1) Hartecoeur, L. L'Histoire de L'Architecture Classique en France, Paris, 1946:
Tomo V, 42 - 45.

\author{
Q Cita / Referencia \\ Benavente Aninat, María Antonia, Dra. Naturaleza y artificio: paisaje fúnebre en la provincia de \\ el Loa. Anales de la Universidad de Chile, VI serie: No13, Agosto 2001 \\ - http://www2.anales.uchile.cl/CDA/an_completa \\ /, 1281 ,SCID\%253D119\%2526ISID\%253D9\%2526ACT\%253D0\%2526PRT\%253D118,00.html
}

-Los planteamientos fúnebres del paisaje

El nuevo proyecto que plantea la selección de terrenos especiales para situar los cementerios a partir de mediados del siglo XIX, habla de un sistema de enterramiento general que no sigue la división por parroquias y cuya administración tampoco se distingue de los otros servicios ciudadanos. Sus trazos planimétricos nos muestran un conjunto dominado por la avenida principal, que conforma un eje paralelo principal del cual parten las otras callejuelas. Esto es muy claro en dos de los cementerios más citadinos de la Provincia como son el de la ciudad de Calama y el de Taltal. No se definen así los de Chiu Chiu, Lasana, Conchi y San Pedro de Atacama. En éstos, una serie de senderos irregulares se abren paso entre muros, nichos, tumbas y escasa vegetación, los que otorgan al conjunto el tono pintoresco de una escena típica nortina.

Al respecto, ningún cementerio posee una estructura arquitectónica y planimétrica homogénea y las diferencias 
que establecemos terminan por ofrecernos dos lecturas encontradas de los camposantos analizados. Por un lado se caracterizan aquellos donde la arquitectura se impone al paisaje: Calama y Taltal y por otro, el "cementerio jardín", en el que las tumbas con sus coloridos adornos de floristería en papel dominan el espacio en el que se localizan: Chiu - Chiu, Conchi, Lasana y San Pedro de Atacama. Se produce aquí un permanente y mantenido "uso social" que se traduce en la especial naturaleza de la parafernalia impuesta por las comunidades locales, en el ritual funerario. Estas formas hablan del cementerio y de su naturaleza con su presencia, pero también sus ausencias pueden llegar a ser y son muy expresivas. Ausencias, vacíos, espacios que expresan distancia entre grupos: extranjeros localizados organizadamente de manera lineal, rodeados de verjas como el caso específico de Tal Tal, los que dejan un gran margen con los "otros" que pertenecen a la población propia del lugar. Espacio que puede señalar el no compromiso social ni de creencias entre ambos vecinos o también el simple vacío que debe existir, cuando los estilos difieren entre un momento $u$ otro. Cualquiera de las dos interpretaciones de igual forma son al momento de dar una mirada al planteo general del panteón. La segregación también ha estado impuesta por el incremento paulatino de "huéspedes" que se establece,desde la instauración de este patrón cementerial decimonómico, fuera de las iglesias. Asunto que no deja de recordarnos el problema existente en siglos anteriores, debido a que por problemas de hacinamiento y salubridad debía dejar de inhumarse en iglesias y parroquias, eligiéndose para esto lugares apropiados, lejos de los márgenes de los poblados.

En la provincia de El Loa encontramos un lenguaje arquitectónico e iconográfico, donde la abstracción y el sentido práctico se resuelven con una concepción profundamente espiritual. El cementerio pasa a ser un símbolo de la conexión entre la arquitectura citadina y el camposanto de manifestación rural. Aspecto traducido muy vividamente entre la típica arquitectura decimonónica de naturaleza industrial plasmada en la iglesia -catedral de Taltal; - por ejemplo, y la expresión de los mausoleos de las familias inglesas que se ubican en el cementerio local. Es la misma materia prima, finas maderas de roble americano que revisten tanto las paredes de parroquias como de las casas fúnebres. Las sostienen hermosas estructuras de fierro y zinc a manera de techos, verjas, ventanas y entradas; modelos urbanísticos y constructivos que planteó el individuo en su vida trasladándolos al espacio seleccionado por el para la posteridad.

Desde otra perspectiva, también son muchos los pequeños y grandes proyectos lamentablemente desaprovechados, donde el actuar rutinario del individuo puede más que la reflexión. Esto quizás tenga su origen en las ocasiones en que estos campos sagrados tienen que asumir los riesgos de la condición del momento, tropezando con el atónito punto de vista de los vivos y de las reglas que reclaman un cementerio repleto de normativas. Quizás también el asunto radica en que los habitantes de estas "ciudades- otras" nunca han expresado su opinión en voz alta y han sido sumergidos bajo su condición localista y rural, más que citadina.

Producto del incremento de la población en los recintos a su vez surgen ampliaciones, emergiendo obras de planteamiento constructivo decimonónico, pero adecuadas estilísticamente a modalidades arquitectónicas actuales o modernas. Son las "obras ex novo", que van a ser habituales en los singulares proyectos de ampliación de los recintos, patrón constante hasta nuestros días. Sin embargo, y con ser el tema de las ampliaciones una cuestión destacada, es mucho más importante el progresivo cambio del paisaje de nuestros cementerios. De forma lenta, las obras públicas que muchas veces son ejecutadas aceleradamente y que en ocasiones poseen cierto aire de provisionalidad, (muros periféricos, ampliación de nicherías), se van adaptando al funcionamiento habitual del servicio, al tiempo que estos cambios se fijan (o debieran fijarse), por medio de intervenciones continuadas, en la imagen del campo santo. Del mismo modo, los espacios libres de los recintos se van poblando de sepulturas, más bien producto de la iniciativa privada más que pública.

A pesar de que tenemos en la zona una clara permanencia histórica de la arquitectura rural nortina, nos resulta muy díficil imaginar a veces, cual debió ser el aspecto de ciudades y pueblos en un momento cualquiera de su historia. Incluso, como sucede en la provincia de El Loa, los conjuntos cementeriales que resultan a primera vista mas homogéneos, presentan intervenciones estructurales diferentes, que en su conjunto marcan un sentido ecléctico muy propio de la zona. El cementerio se convierte así en un "palimpsesto", sobre el cual los diferentes momentos de la tradición han ido dejando impreso su estilo. Es precisamente éste uno de los mayores atractivos de este "espacio artificial" que compone la estructura cementerial y por ende la díficil trama urbana-social. La tradición de honrar a los muertos exige la cercanía de los mismos, solo así puede entenderse que continúe presente en el inconsciente colectivo de la mayoría de las comunidades locales nortinas, una permanente reflexión del sentido que significa el morir.

Prima aquí el sentir de la "muerte social", expresión que manifiesta el interés de la comunidad toda, no sólo en la participación del rito fúnebre, al morir un miembro del grupo; sino que también en lo que es el planteo constructivo de los panteones. Se describen desde esta perspectiva una producción masiva de estructuras arquitectónicas que repiten conscientemente fórmulas establecidas, como son las hileras de nicheríos de blanca, casi alba formalidad estructural, otorgada por la cal, que contrasta con el café inalterable del desierto circundante. Patrón que sólo se altera por los adornos y la seca pero colorida floristería adosada en lápidas y verjas. Es la iniciativa pública, que se acerca al cementerio:

a) al mantener la tradición social tan típica de las comunidades del área y que mejor que traducirla a través de lo más permanente que existe en los individuos como es el sistema simbólico. Aquí el ritual mortuorio y todo lo que éste implica adquiere el aspecto más relevante.

b) También al otorgar un mínimo de dignidad a las sepulturas de los grupos menos favorecidos y

c) al controlar la complicada tarea de la vecindad del cementerio.

Una mirada más citadina nos señala que los cementerios de la Provincia no se alejan del mundo circundante. Visualizamos también, la introducción paulatina de lo que se tipifica como "arquitectura civil". Es la incorporación al contexto fúnebre nortino de panteones, tumbas o mausoleos sin expresión artística definida manifiestan una una orientación religiosa particular. Es la expresión de la "muerte del otro". Difunto que emerge solitario dentro de un contexto fúnebre, caracterizado mayormente por un patrón bastante rígido en lo que se refiere a la expresión arquitectónica, que se distingue por su reiteración, tanto en su patrón constructivo como en la iconografía que la acompaña. Iconografía sincrética, expresada en una permanente y persuasiva utilización dialéctica de dos elementos: el retrato del difunto y el corazón de Jesucristo o la Virgen María. El primero es la expresión viva de lo que es la individualidad, la importancia del personaje socialmente hablando, pero que se localiza en un contexto 
fúnebre. Esto último será otorgado por la naturaleza en que se situa la fotografía; por tanto aquí se cumple totalmente la significación del contexto fúnebre. Dicha acción se ve vivamente cultivada gracias a los deudos que mantienen la parafernalia propia de la actividad del difunto y de los seres que lo rodearon en vida. Complementan este contexto figuraciones de perros, gatos, casas de muñecas, fotos, flores, adornos múltiples; los que en pequeña escala son sagradamente mantenidos. En algunos casos, figuraciones tapadas por típicos "visillos" (cortinas de encaje), mantienen al difunto separado del mundo real. Al tratarlo con este velo lo sitúan temporalmente a gusto en el momento de su vida. Dicho de otro modo es la "muerte exclusión". Expresión que manifiesta un sentir de los deudos o del propio difunto. Ambos sentimientos reflejan el alejamiento, la separación, impuesta al segregarse del contexto. Mirado desde la perspectiva de los deudos, es dejar de manifiesto que el personaje que se enterró allí sólo pertenece a tal grupo y el resto no debe observarlo; subliminalmente el individuo establece un cerco. En el caso del corazón de Cristo y la figuración de María, es la adscripción religiosa de la que el difunto se apropia. Es la protección y amparo necesarios, expresados muchas veces por los deudos a su ser querido, a menudo sin que esta fuera la voluntad del propio fallecido.

Esta manera de observar no debe confundirnos con otro tipo de manifestación fúnebre muy común. Es la "muerte marginada", que representa a aquellos difuntos, que por el paso del tiempo, o por que no tienen quien les cuide su lugar están marginados. Este tipo de segregación incluso es espacial y corresponde al sitio que ocupan los primeros habitantes de los panteones, quedando situados por el paso del tiempo en los márgenes del contexto fúnebre. Es el paso del tiempo y la incorporación de nuevos planteos constructivos que logra marginar al individuo, a su historia y su significación social. Es la réplica de toda estructuración, donde lo urbano, lo moderno, el uso del espacio, en síntesis deben adecuarse a las demandas del momento. Alcanzamos aquí un punto de reflexión significativo en el recorrido general que llevamos a cabo en los cementerios de la provincia de el Loa.

Hasta el momento nuestro recorrido por los cementerios de la II Región se ha ocupado del tiempo de su génesis histórica desde el siglo XIX hasta nuestros días. También hemos hablado de ellos sin referencia expresa a su realidad parcial, pero si de una forma conjunta.

Nos hemos interesado en el lugar que ocupan los cementerios y del diálogo que estos espacios mantienen con la comunidad, ocultando discretamente su trazado, su simbolismo y otras formas de expresión propias de la parafernalia fúnebre, sin tratar, en ningún modo, de realizar un inventario de las particularidades formales (que las hay), de los cementerios de la zona. Tampoco hemos pretendido reducirlos a un patrón homologable a escala nacional, pues las similitudes que existen entre cada uno de ellos se diluyen en sus características particulares. A su vez no nos ha intimidado la existencia de "invariantes" locales o provinciales, pues pensamos que ello es propio de la espontaneidad y de la libertad creativa del hecho arquitectónico rural nortino. Con este estudio solo hemos pretendido mostrar y esbozar la realidad de los cementerios de la región. Pensamos que tenemos una obligación "didáctica" en este trabajo, ya que son tantas las miradas y filtros que juegan entre el observador y los cementerios, que lo mínimo que estos merecen, es una "observación limpia". Nos referimos aquí a que nuestra manera de ver ha estado libre de prejuicios y supersticiones, al margen de las creencias religiosas, valoraciones estéticas o laudatorias. Enseñar y mirar los cementerios ha sido una de la principales obligaciones que nos hemos impuesto, por tanto el trabajo en terreno ha sido fundamental para comparar, establecer paralelismos y poder percibir sus diferencias. Al respecto también hemos podido debatir ampliamente acerca de las peculiaridades de los cementerios nortinos, sobre los distintos elementos que los definen, como también de los tipos arquitectónicos que los diferencian. Sería bastante complejo localizar indicadores propios que, despegados de su contexto funerario, poseyeran una "esencia funeraria" sobre la cual no tuviéramos dudas.

Esta forma de mirar el problema, nos garantiza que todo el conjunto cementerial se plantea a partir de un enfoque que considera al cementerio y todos los elementos que lo conforman, como constitutivos de un sólo contexto que tiene como única función la funeraria. En este sentido coincidimos en "que el cementerio es el producto de una suma de realidades arquitectónicas y urbanísticas y, por lo tanto, lo reconocemos como hecho complejo.." ( Rodríguez Barberan, J 1993: 55).

En este sentido la relación ciudad- cementerio es un elemento importante, pero es de relevancia abordar otro indicador espacial, como es el área de afección de los panteones. Nos referimos a las cercas, murallas, árboles, portadas, capillas, tumbas; elementos que en su conjunto, nos darán cuenta de la forma contextual cementerial de la II Región. Mirado así, el análisis contextual fúnebre considera la forma espacial como el primer referente a observar. Interesa aquí dejar en claro que en toda forma cultural de ver el espacio queda implícita la existencia de un orden, cuyo objetivo dice relación específica con la expresión significativa que queremos otorgar a dicho lugar. Aspecto claramente definido tanto por normas y reglas apropiadas a los asuntos cementeriales, como también aquellas tan fielmente sostenidas por las tradiciones comunitarias.

El espacio fúnebre, analizado culturalmente, cumple por tanto un objetivo ritual. Aquí el rito llega a la expresión cúlmine de la parafernalia dedicada a la muerte. Es el último lugar en que tanto el difunto como el deudo cumplen al mismo tiempo un mismo pasaje: el rito de la muerte. Todo esta debidamente reglamentado y por ende también la forma de enfrentar el espacio. Este terreno mortuorio debe otorgar tranquilidad a los difuntos, para que cumpla su finalidad debe poseer una racionalidad en su ordenación y erección de sus edificaciones. Desde esta perspectiva nos encontramos con un primer elemento, que es el cerramiento. La primera barrera que tantos difunto como deudos deben enfrentar y traspasar es la cerca.

La cerca en los cementerios se inscribe como la primera frontera tangible. Es la imagen exterior que circunscribe un espacio pleno de connotaciones "tanto si aparecen tras ella la silueta de los impases y la coronación de mausoleos y nichos, como si ocultaran totalmente el recinto que sabe transmitir las especiales características del lugar que protege - incluso cuando cede su protagonismo a las plantas ...adivinamos en ella un carácter disuasorio de hecho, su primera misión es la de proteger las tumbas de cualquier posible daño, ya sea el inconsciente de los animales, ya aquel que en el hombre obedece a oscuras y diversas causas" ( Rodríguez Barderan I. 1993: 55).

Esta habitual "condición extramuros" del cementerio se traduce en una doble lectura, por un lado priva al panteón de la influencia urbana y por otro, al aislarlo, le entrega la seguridad, el silencio y el aislamiento necesarios al difunto y sus deudos que solamente tales cercas pueden otorgar. Referente a los cementerios de la Región (Chiu-Chiu; Calama, San Pedro de Atacama, Tal Tal; Conchi, Lasana) por su especial emplazamiento, ninguno 
evita la construcción del cerco, incluso en algunos de ellos se le adosan largas nicherías. Elementos que no sabemos, si sirven de apoyo al muro o si su construción fue causa de falta de espacio o fueron los primeros difuntos los que inauguraron este "cerco mortuorio". Este elemento actúa como indicador temporal. Es un mudo testigo del crecimiento y ampliación, que fácilmente se advierte al observar los cementerios. La diferencia entre materiales y fórmulas constructivas nos avisan estos cambios. En la mayoría de los panteones conviven los primitivos cerramientos (como es el caso del cementerio de Chiu Chiu y San Pedro de Atacama), con las nuevas obras de sillería, como es en el caso del recinto sagrado de Calama. A su vez son signos de identidad regional, sobre todo si consideramos en este planteamiento las materias primas de su construcción. Son lajas, el calcáreo del lugar, el ocre del terreno, la cal blanca, todos elementos que conforman una mezcla típica que corre en forma sinuosa pero continua, demarcando un cuadrado o rectángulo solamente interrumpido por una central verja de fierro forjado, que imponente otorga función al espacio cerrado. La diferencia existe entre uno y otro panteón, en relación al cerramiento y es debida a la naturaleza y pendiente del terreno. Cuando el terreno es plano, como el cementerio de Calama, los muros se visualizan altos, imponentes, parejos. Cuando el panteón se localiza en pendiente como en Chiu-Chiu, los muros asemejan ser desnivelados, aunque de modo estricto no lo sean. Es el juego de la perspectiva, la realidad y el punto específico en que se localiza el observador. Al visualizar este espacio sagrado, esta forma de observar nos permite a su vez, enfocar la mirada desde el interior hacia afuera. Lo normal es que el muro perimetral al interior sea idéntico que al exterior, con la excepción recurrente que en el interior este cerco se aprovecha para sostener las nicherías, y las bóvedas trasdosadas, característica heredada de enterramientos de parroquias e iglesias. Podríamos señalar que, incluso los difuntos quisieran continuar apoyandose en "muros seguros", cercanos al poder divino. También podemos enlazar el segundo nivel de entierros con respecto al cerco. Nos referimos a aquellas tumbas simples que se sitúan en hileras con una cruz en la testera y que dan la espalda al cerramiento. Aquí la centralidad y orientación está dada en relación al indicador principal de estos panteones nortinos, como son las grandes cruces que sobresalen tanto en su alto como en tamaño y que se sitúan centralmente en el espacio fúnebre.

Los muros son la primera "barrera" existente entre el espacio dedicado a la muerte y su entorno. Otra frontera a considerar es la portada. Esta garantiza el acceso al interior del cementerio a dos individuos: el difunto y el deudo. Por esta razón la fuerza simbólica que está detrás de este acceso, pasa de ser una simple fachada, a la expresión de un íntimo sentimiento de que accediendo a ese recinto, la connotación entre el paso de la vida a la muerte es algo tangible, algo verdadero, pensamiento escamoteado en vida. Aunque la resolución arquitectónica de la entrada al camposanto sea simple, el hecho de ser central y el utilitarismo que denota, se pliega a la función trascendente que esta tiene. Podríamos incluso acotar que la entrada a través de su fachada, se subordina a la intención que de esta se deduce es decir, la relación entre la vida y la muerte, entre la parafernalia mortuoria y el sentimiento que de esta se interpreta. Es la clara racionalización de la eficiencia existente entre el espacio sagrado y el profano. Son espacios que delatan a la naturaleza del invitado, que traspasa este umbral. Estas portadas reciben al difunto y al deudo; despiden al deudo que deja en su aposento definitivo al fallecido, pero también siempre está abierta para el ingreso gratuito de quienes sienten que esta residencia fúnebre representa un terreno neutral de paz y caridad. Que en síntesis expresa ampliamente la memoria colectiva de quienes cobija para siempre.

Los panteones de la II Región a través de sus portadas mantienen un patrón arquitectónico severo en su estilo. Solamente se materializan en grandes verjas de fierro forjado con una cruz en el centro, a éstas se adosan dos pilares laterales a modo de sostén. Esto quizás explique la adopción de ésta fórmula en lugares tan amplios como la II región, ya que encontramos portadas y verjas similares tanto en ciudades de la costa (Tocopilla, Mejillones, Tal Tal) como en ciudades interiores (Calama) o zonas rurales (San Pedro de Atacama, Chiu-Chiu, Ayquina).

Este espacio de tránsito refleja:

"..... una visión filtrada del interior, con los efectos psicológicos que ello supone. Frente a la opacidad que predomina en aquellas fachadas donde el cínico vano es el de entrada, la solución de pilares y verjas, combinadas con un pequeño recinto ajardinado, elimina los prejuicios de una mirada que en los demás casos se enfrenta, a través de la portada y sin mediación alguna, a las sepulturas" (Hartecoeur, 1946:44)

Contextualmente podemos afirmar que existe una total ausencia de propuestas arquitectónicas para la Provincia. Aspecto que difiere de otros cementerios chilenos. En éstos, no sólo los espacios arquitectónicos están especialmente estructurados; sino que también las obras realizadas por los urbanistas suelen ser modelos elaborados para cada cliente pagandose el trabajo, sino que también la exclusividad exigida por el mandante. Apoyan esta práctica la enorme difusión que se otorga a los catálogos de monumentos funerarios o también de cementerios italianos y franceses. Obras muy apropiadas para que a medidos del XIX sean consideradas en la construcción de panteones como el General de Santiago de Chile y el Católico de Santiago.

Anexo a esta monumentalidad se asocian los denominados servicios anexos, que cumplen el objetivo fundamental de dar cobijo y asistencia a deudos. Estas son las obras dedicadas a los "servicios cementeriales". Son las dependencias que surgen asociadas a las necesidades que estos requieren: capillas, pabellones administrativos, areas de mantenimientos para el personal y el público. En el conjunto cementerial del norte, éstas dependencias no constituyen grandes edificaciones; incluso sólo las encontramos en los panteones de Calama, Tal Tal, Tocopilla, Mejillones. En éstos sólo se ha habilitado una única sala para realizar labores administrativas, acoger a deudos y público en general.

En relación con las variantes estilísticas que se pueden deducir de las dependencias de los cementerios hay que dividirlas en dos: la capilla que va a representar la construcción más elaborada; en cambio el resto de las edificaciones va a repetir planteos arquitectónicos comunes al ámbito citadino. Existen algunos casos como el cementerio de Tal Tal donde es reiterativa la aplicación de fórmulas constructivas de naturaleza industrial, formas urbanísticas de la ciudad que se trasladan al ámbito cementerial. Puede pensarse aquí que pesan más razones de orden económico, sacrificando la estética del conjunto.

\section{RECAPITULANDO}

La Provincia de El Loa y su paisaje fúnebre presenta un patrón cementerial muy semejante a los modelos 
cementeriales de la capital. A la planificación primera, con recintos rectangulares de estirpe academicista, se van superponiendo sucesivas ampliaciones en función de las necesidades de las comunidades. La imagen geométrica de sus viarios con callejuelas claramente definidas, de significativos elementos arquitectónicos de naturaleza clasicista (portada, cerramientos, pórticos interiores cuando los hay), van siendo desvirtuados por el añadido de nuevos espacios y símbolos; signos ambos del paso del tiempo.

El paisaje interior también es transformado. La ingenua rusticidad de las primeras tumbas de suelo, su connotación entre popular y ecléctica, los edículos que dan acceso a las tumbas dejan paso a las formas más cuidadas, pero también más frías de las grandes estructuras funerarias anexas. La falta de suelo y las necesidades surgidas ante el aumento del "particular vecindario" terminan por ocultar la visión anterior del proyecto, sustituyéndola por una mas cercana a la realidad contemporánea abstracta.

La regularidad de la topografía de la Provincia facilita los asentamientos ordenados, ya que impulsa a que los cementerios se derramen, sin plan previo alguno, Este es el caso del cementerio de Chiu Chiu. Este tipo de cementerio, reservado siempre a pequeñas localidades, consigue sin proponérselo el ideal buscado: la armonía de la obra del hombre con la naturaleza. Sin recurrir a las grandes obras arquitectónicas y trazados que fuerzan el terreno, los cementerios de Chiu Chiu y San Pedro de Atacama, traducen exactamente las matices sociales y culturales a los cuales sirven.

La cerca, la sencilla portada de ambos panteones, dan paso a un espacio donde cada tumba posee un valor individual. Este sin embargo, nunca supera la emoción de la mirada que se puede dirigir al conjunto de la especial perspectiva que ofrece al visitante. Calama nos aporta, en cambio, el caso típico del cementerio que se edifica en el siglo XIX, proyectado por constructores provinciales y municipales, tal como ordena la ley de la época. Este cementerio responde a un plan cuidadosamente trazado. Se asienta sobre terrenos sin desniveles, que permiten al constructor desarrollar un modelo academicista muy común, de bastante semejanza a otras de naturaleza provincial. Aquí el recinto cementerial queda dividido por un gran eje de penetración, que une la portada con la pila central de construcción actual. El tránsito se resuelve en calles y callejuelas que se reparten de modo desordenado entre sepulturas de suelo, mausoleos y nicherías. La vegetación aquí conquista los espacios libres buscando la vecindad de las tumbas para embellecerlas. No se puede pensar, en todo caso, que arbustos, árboles y flores irradien la imagen bucólica de un "cementerio ajardinado" típicamente citadino. Aquí la arquitectura plantea sus mayores exigencias, quedando el jardín a la sombra del descuido, aspecto que es frecuente en cementerios como éste.

En todos los conjuntos cementeriales de la Provincia observamos que las primeras estructuras arquitectónicas se ven alteradas y modificadas por imagenes más recientes. Se destaca el "palimpsesto" que parte desde la portada hasta alcanzar la repetida secuencia de nicherías, tumbas de suelo y enormes mausoleos reflejando variadas interpretaciones de ideas y simbolismos, que van desde un academicismo severo hasta lo "Kitsch".

Sin embargo, podemos señalar que en su totalidad los conjuntos cementeriales logran una total identificación con su entorno. Son lugares bien ventilados, distantes de los poblados, condición demandada por la ley para la creación de cementerios, normativa aplicada por individuos que nunca pudieron imaginarse que producirían tal revitalización en la naturaleza de las obras arquitectónicas. Reglas que no sólo cambiarían los lugares de inhumación, sino que éstos se transformarían en verdaderos catálogos de obras de arte, o en "Museos" que permiten entender a la sociedad en su totalidad, y el papel que ocupa el fenómeno de la muerte tanto en su ámbito privado como público.

- Bibliografía

Aries, Philippe. Images of man and Death. Cambridge, England, Harvard University Press, 1985, $272 p$

Aries, Philippe. El hombre ante la muerte, Madrid, Taurus, 1983, 522 p.

Benavente A. M $\mathrm{M}^{\mathrm{a}}$ Antonia . Cementerio General de Santiago de Chile; Una aproximación histórica, Oviedo, Universidad de Oviedo, 1999 (Tesis doctoral).

Benavente A. Ma Antonia. Una visión acerca de la Muerte. (En: II Congreso Chileno de Antropología, Valdivia, octubre 1995)

Benavente A. Ma Antonia . Las vanidades en la iconografía funeraria chilena. (En : Anales de la Universidad de Chile, sexta serie № 6 , diciembre de 1997, pp 41-57)

Benavente A. Ma Antonia y Bermejo L, Carmen. Síntesis Histórica de la funebría en Chile. (En : Revista Chilena de Historia y Geografía. Santiago, Sociedad Chilena de Historia y Geografía, 1996, № 162 , p. 137- 162)

Bermejo S., Carmen . Arte y Arquitectura Funeraria, Oviedo, Universidad de Oviedo, 1998, 329 p.

Bialostocki, J. Estilo e Iconografía. Contribución a una ciencia de las artes. Barcelona, 1972, 205 p.

Cruz, Isabel. La muerte, transfiguración de la vida. Santiago, Ediciones Universidad Católica de Chile, 1997, $326 \mathrm{p}$.

Hautecoeur, L. Histoire de I'Architecture Classique en France. Paris, A et J. Picard, 1946.

Hertz, Robert. La Muerte, la mano derecha México, Alianza Editorial, 1990

León, Marco Antonio : Sepultura Sagrada, tumba profana: Santiago Chile, DIBAM, 1997 
Morales Saro, M C. El indiano como impulsador de cementerio y clienta de Arte funerario. (En Actas del I Encuentro Internacional sobre los cementerios contemporáneas, Sevilla, 1993)

Morin, Edgar. El hombre y la Muerte, Barcelona ,ed Kairos, 1994

Ragon, Michel. L'espace de la mort. Essai sur L'Architecture funeraire. Paris, Albin Michel, 1981, $340 \mathrm{p}$.

Pfandl, L. Cultura y Costumbres del pueblo Español en los siglos XVI y XVII. Barcelona, sed, 1929

Vincent- Thomas, L. Antropología de la muerte, México, FCE, 1975, 640 p.

Vovelle, M. La mort et L'occidente. De 1300 a nos Jours. Paris, sed, 1983

Resumen | Los planteamientos fúnebres del paisaje | Bibliografía | Versión Completa (Imprimir)

Sitio desarrollado por SISIB - Universidad de Chile 